\title{
Academic Practice/Design Interventions: An Activity-Based Design Course for Conceptualizing Failure and Factor of Safety
}

\section{Mr. Nikolaos E. Vitoroulis Jr, Stevens Institute of Technology}

Nikolaos Vitoroulis supervises the Engineering Design Laboratories at Stevens Institute of Technology. He earned his Bachelor and Master of Mechanical Engineering at Stevens and specialized in Robotics, Mechatronics, and Manufacturing. As a member of the Innovation, Design \& Entrepreneurship at Stevens (IDEaS) team, he works with the development team to update and generate engineering curriculum content. His past industrial experiences include: Production \& Packaging Engineering at L'Oreal, Medical Device Development at Ethicon, and Mechanical Design of Commercial Camera Robotics.

\section{Mr. Changhong Zhang \\ Dr. Kishore Pochiraju, Stevens Institute of Technology}

Kishore Pochiraju is the Associate Dean for Undergraduate Education and a Professor in the Mechanical Engineering department at Stevens Institute of Technology. He recently served as the Founding Director of the Innovation, Design and Entrepreneurship Program at Stevens ( IDEaS) and prior to that, as the Director of the Design and Manufacturing Institute, a research center at Stevens. Prof. Pochiraju received his Ph.D. in 1993 from Drexel University and joined Stevens after working as a postdoctoral fellow at the University of Delaware. His expertise spans product design, advanced manufacturing, materials insertion, and knowledge-based systems integration. His current externally-funded research is on the design of real-time lightweight robotic systems, high-temperature materials, and micro-/nano-scale devices. He is a member of ASME, ASEE and the American Society for Composites (ASC). 


\section{An Activity-Based Design Course for Conceptualizing Failure and Factor of Safety}

Abstract - Teaching design throughout the eight-semesters of undergraduate studies, termed as the design spine, is a hallmark of the engineering curriculum at our university. As most engineering designs must meet some level of mechanical performance requirements, this thirdsemester design spine course focuses on the design of load carrying components. This course requires the introductory course on mechanics of materials as either a prerequisite or a corequisite. The pedagogy in this course centers on introducing design vectors that span material behavior, geometry choices, and manufacturing processes in a laboratory environment while using team-based learning methods. We recently developed a series of activities that introduce material behavior, failure modes, uncertainty in material properties, understanding the factor of safety in design, and culminating in a planar truss design and validation exercise. The course presents the evolution of complexity in the design vector through experiments that focus on design for tensile strength (material selection for strength), compression/buckling, (material selection and geometry design for stiffness enhancement), and joint shearing, (material selection, geometry design and process selection). Student teams analyze the statistical variability and parameter uncertainty using the data generated by all teams enrolled in the course. Using a data-driven approach, we introduce and reinforce the concept of factor of safety using simple reliability theories that model uncertainty in component strength. The course culminates the design, testing and optimization of a space-spanning truss using the data generated from the earlier activities. The student performance is assessed directly from the student teams' data submissions and lab/design report grades, and indirectly through learning outcome surveys. Student teamwork performance is measured by a public peer-evaluation rating scheme, which also feeds back to the team selection process. This paper presents the activities, the instructional methods, assessment data for the pilot implementations, and a comparison of the student performance from the prior years.

\section{Introduction}

This course is the third of eight core engineering design courses that span the undergraduate educational career, matching a model that has shown effective in developing a systems level thinking. [1] This third-semester engineering course provides a series of activities focused on the design of load bearing components set in a laboratory environment with team-based learning. The design process is guided by the concept of a design vector consists of design parameters. The topics covered in the activities are placed in an order which reflect the growth and complexity of the design vector. The three main mechanical loads that are studied are tension, compression, and shear, each increasing the design vector complexity in their respective order. The theoretical behavior and equations are introduced and presented in the beginning of an activity; this is done to reinforce the concurrent co-requisite or refresh the prerequisite mechanics 
of materials course. The activities aim to decompose the equations into the separate design vectors, and to demonstrate the behavior in a physical test or application. The activities will also showcase different modes of failure of mechanical components, and the uncertainty that lies within the material itself or within the process of manufacturing. Focusing the activities in a selflearning group environment, students' learning experience will be greatly improved in tandem with their soft skills: reporting, communications, and planning [2].

To promote a better interest in the overall learning outcomes, the series of activities are structured to combine their knowledge and culminate to a final project competition for the design of a planar-truss. A competition can bolster the intellectual maturity of students who begin to realize that there is not just one right answer to a problem. It also encourages the students to identify many problems, evaluate the solutions, work in a group, and apply concepts directly [3]$[5]$.

The class is held across fourteen, three-hour, sessions within a semester, and is comprised of a maximum of 24 students and 1 instructor. Nine out of the fourteen sessions are dedicated to the primary activities listed below, while the remaining comprise of days for hands-on clinics, presentation, and an open-ended design scenario activity. Based on each student's background, skill-set, and major, the instructor places the students in carefully selected groups of 3 to help promote a better learning experience [6]. This method of group formation is also carried out in the freshmen level design course to help balance the different backgrounds, and prior experiences of students to make well-functioning teams. Individuals, at the end of the class, rate themselves and each other in the overall group performance based on quantity and quality of contributing efforts, and overall communication skills. A mid-term and end of semester survey is given out to assess the students to gauge their learning and feelings towards the material, and to gauge their learning outcomes (listed in full below in Table 1). By monitoring the graded assignments, actively probing for instantaneous feedback, and evaluating survey results, instructors and the course development team can refocus their teaching and help make the students' learning more efficient and effective [6]. The continuous collection and evaluation of this data is paramount for promoting positive course development [7].

Table 1 - Activities Covering Course Learning Outcomes

\begin{tabular}{|l|l|c|}
\hline Learning Outcome & Criterion & Activity \\
\hline $\begin{array}{l}\text { L1-Resolve mechanical problems involving equilibrium, axial } \\
\text { and flexural stresses/strains, and safety factors. }\end{array}$ & $\begin{array}{l}\text { Engineering } \\
\text { Foundations }\end{array}$ & $1-5$ \\
\hline $\begin{array}{l}\text { L2-The students shall be able to conduct experiments, analyze } \\
\text { data, and identify sources of error in discrepancies between the } \\
\text { theoretical and experimental results. }\end{array}$ & Experimentation & $1-4$ \\
\hline $\begin{array}{l}\text { L3-The students shall be able to "design" an experimental } \\
\text { procedure to collect the data necessary to achieve experimental } \\
\text { objectives. }\end{array}$ & Experimentation & $2-3$ \\
\hline
\end{tabular}




\begin{tabular}{|l|l|l|}
\hline $\begin{array}{l}\text { L4-The students shall be able to use computer based } \\
\text { computational tools such as EXCEL to find graphical, } \\
\text { numerical, statistical, and analytic solutions to problems. }\end{array}$ & Tools & $1-4$ \\
\hline $\begin{array}{l}\text { L5-The students shall individually be able to function } \\
\text { effectively on teams by acting cooperatively and honoring } \\
\text { individual commitments to the team when engaged in group } \\
\text { projects. }\end{array}$ & Teamwork & 5 \\
\hline $\begin{array}{l}\text { L6 (a-b)-The students will be able to demonstrate effective } \\
\text { communications by delivering appropriate (a)oral and } \\
\text { (b)written technical presentations. }\end{array}$ & Communications & 5 \\
\hline
\end{tabular}

Table 1: List of Course Learning Outcomes listed with associated criterion fulfillment and class activity designed to teach corresponding outcome. See Activity list below for full detail.

This laboratory leaning environment is designed to move away from the traditional classroom setting and methods of teaching. The theoretical equations and principles are kept at a minimum, as they are covered in more detail in a concurrent Mechanics of Solids course. By implementing a team-based learning environment in a laboratory setting, we are able to improve the overall learning experience [7] [8]. The team-based activities are designed to take and utilize the acquired lecture-based knowledge, which fall into the lowest level of Bloom's (1956) taxonomy levels: Knowledge, and evolve into Bloom's highest cognitive level: Evaluation. [9]. The taxonomy of cognitive develop, according to Bloom, listed in ascending order are: Knowledge, Comprehension, Application, Analysis, Synthesis, and Evaluation [9].

The development of advanced cognitive learning in the activities will be outlined in brief, beginning with the aforementioned lecture-based Knowledge level. Through hands-on, demonstrative learning activities, the gap between written equation and physical realization are reduced (Comprehension). Students apply the principles learned and develop an experiment to gather data (Application). Team members collaborate on analyzing acquired data (Analysis), develop hypotheses and engineering designs (Synthesis), and ultimately test and evaluate their design's performance (Evaluation). By implementing these methods of learning, students have a more engaging and "fun" experience, and are successfully introduced into the workforce from having developed strong team-building communication skills, which is marketable to employers [8].

\section{Activities}

A common component between all of these activities is the selection of material of 260 Cartridge Brass (360 Brass for tensile samples). The intent of using a single material is two-fold: brass will be used in the final project of constructing a planar-truss, and in turn, keeping with the same material characteristic and findings in antecedent activities can be carried over. By isolating the material selection, the material behaviors, modes of failure, and the values associated, the 
materials can be compared equally. The following is a brief description of each activity as it takes place in the laboratory, followed by the activities learning outcome.

Activity 1 - Tensile Strength Students are given an engineering sample of 360 Brass and perform several tensile pulling tests. The raw data is exported and then generated into an engineering stress vs. strain diagram, (Fig. 1), by the students. The core features of the diagram, such as yield strength, $0.2 \%$ offset yield, UTS, etc., are explained and the students are to then identify these features within their diagrams.

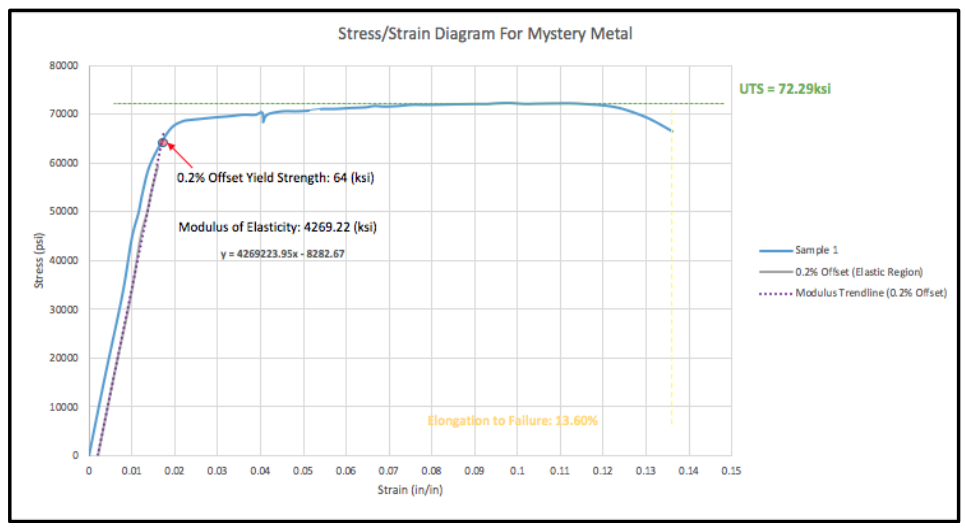

Figure 1: Student generated example of Stress vs. Strain Diagram from Activity 1. Fundamental material properties are observed and Microsoft's EXCEL is used to translate the test points into graphical data.

The learning outcomes of this activity are for the students to be able to produce and understand the components of an engineering stress vs. strain diagram, add a trend line to the dataset, determine the modulus of elasticity and $0.2 \%$ offset yield, and to produce proper graphical representations of their data.

Activity 2 - Compression (Buckling) - Brass Characterization The first activity that explores compressive loads begins with an introduction to Euler's Buckling and the calculations of Moments of Inertias. Stock materials of the structure members that will constitute the planartruss project are divided into various lengths and are subjected to a compressive test with the peak, critical buckling, and load; Data is recorded and then evaluated. The actual vs. theoretical buckling loads for each unsupported length is compared and the actual values are compiled and a trend-line is generated. This trend-line equation then becomes the characteristic brass equation used when predicting the final buckling load of their theoretical truss design (Fig. 2). 


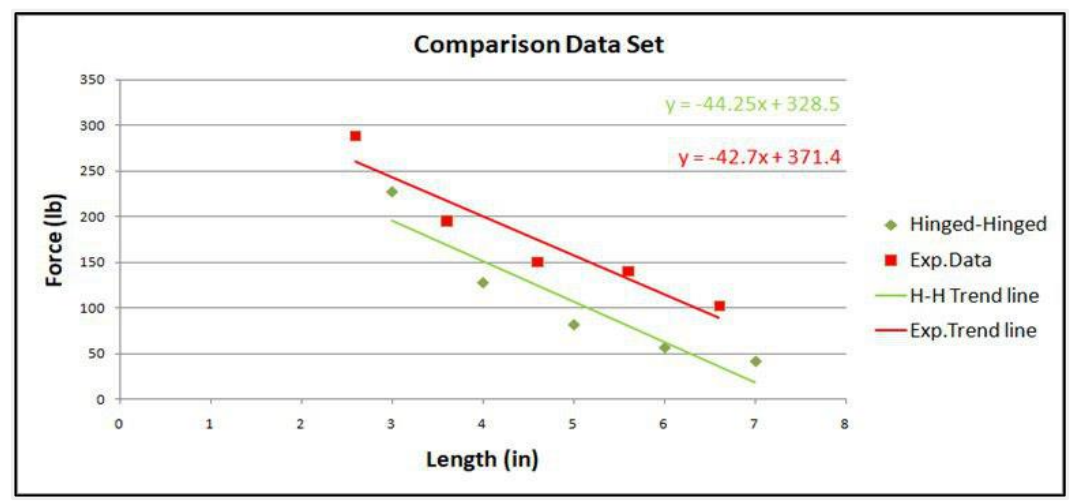

Figure 2: Class Sample Data and resulting characteristic equation for brass. Similar trend-lines will determine the equation used to predict failing load of planar-truss.

This activity aims to develop data-collecting and data-interpreting skills by characterizing a material's property, and bridge the theory vs. reality gap by using this information later in the design and realization of a planar truss.

Activity 3 - Compression (Buckling) - Cross Sections \& Moment of Inertia The second activity focusing on compressive loads looks at the effects of a column' geometry and the critical buckling load. Brass columns, both tubes and rods, of different shapes are both theoretically calculated (Fig. 3), and actually tested to compare the results (Fig. 4). The primary learning outcome of this lab is to emphasize that the geometry (i.e. the Moment of Inertia) is the driver of the column's strength and not just the total cross-sectional area.

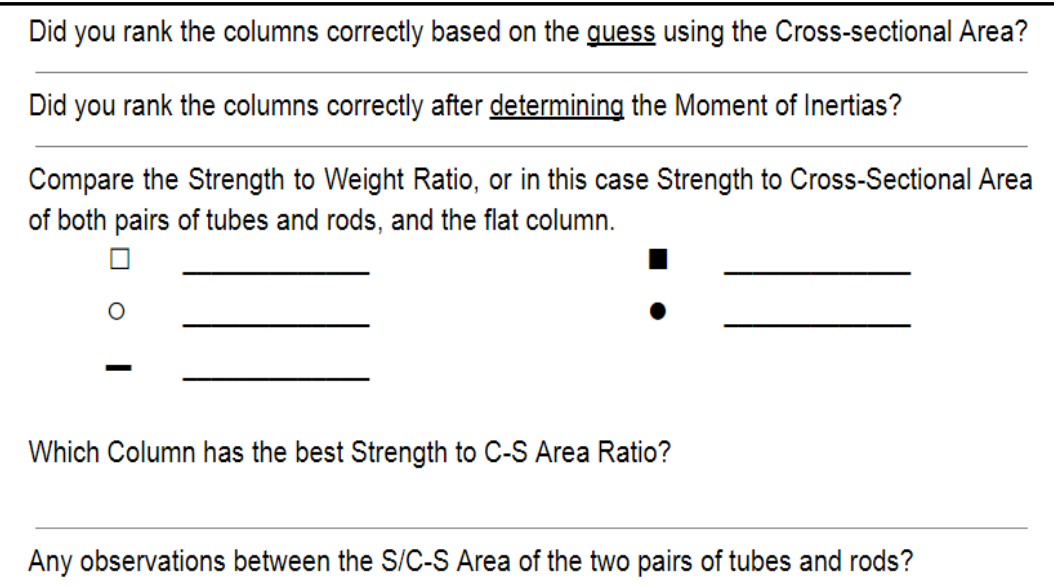

Figure 3: Excerpt from Buckling Activity Worksheet. Emphasis is made on understanding concepts beyond executing a calculation, such as concluding what information can and cannot be determined by certain parameters. 


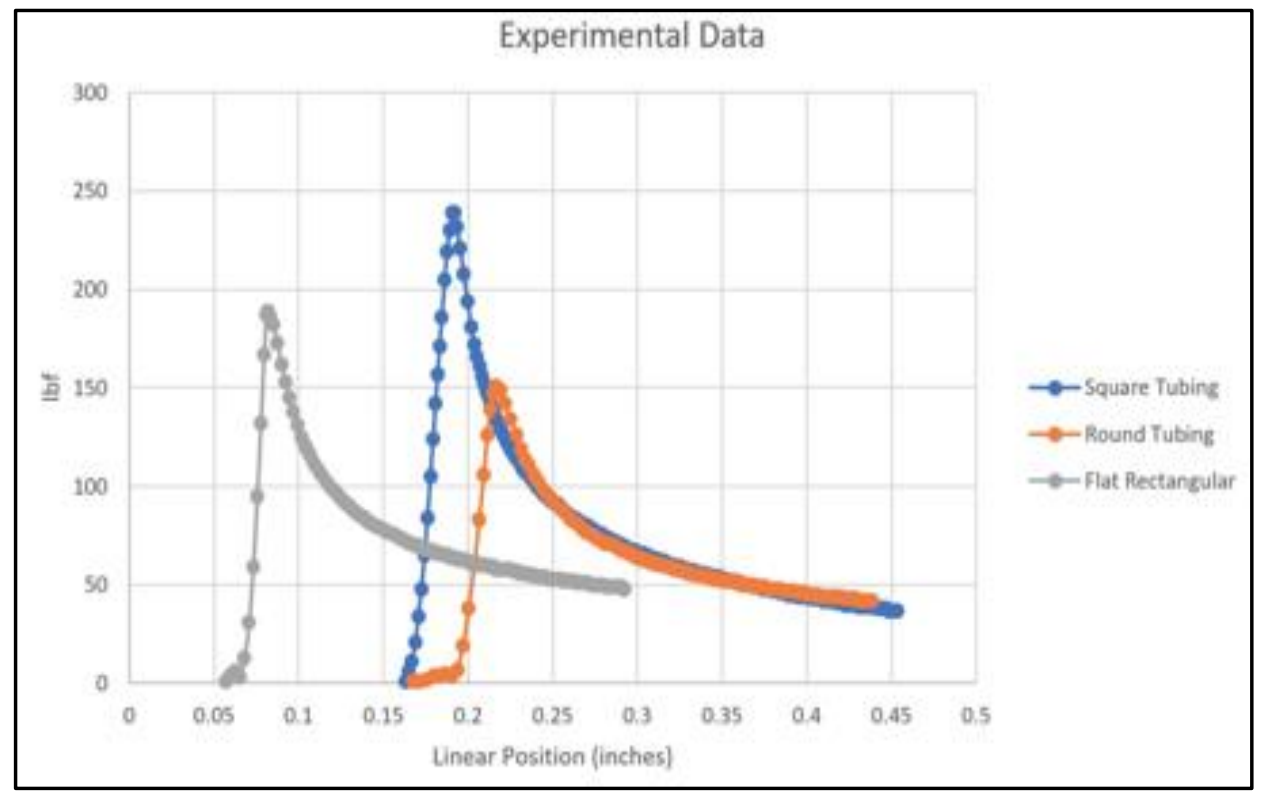

Figure 4: Student produced graph of buckling loads for different cross-section columns. Selfperformed tests show quantitative real-time material behavior.

\section{Activity 4 - Joints \& Shear - Strength Uncertainty and Variability}

Students are tasked with fabricating and experimentally derived test data of soldered brass lapjoints. These soldered joints are fabricated in-class and closely resemble the joining technique used when gusseting the planar truss project (Fig.5). The students are then required to analyze the data and determine if a lap joint design can be synthesized to fail within a specified load range, and for the failure to be a joint-failure. Students are encouraged to explore different graph types and iterate which type best represents their dataset (Fig.6), and required to develop a histogram to categorize their data (Fig. 7). A similar experiment, conducted at West Point Military Academy [10], demonstrating factor of safety while emphasizing an efficient design, rather than an under or over engineered design, proved effective in demonstrating a material's properties while considering defects in the process of joining. The classrooms' sample data typically shows a significant inconsistency with the strength of the lap joint (when failing at the joint), and a lesser variation in the brass material properties (when failing due to yield). An emphasis on the inherent uncertainty of joining processes, rather than the consistency of the brass material itself, is discussed during the analysis of the data. Students then develop graphical representations of the dataset that generate valuable insight to quantify process errors and ways improve process control. 


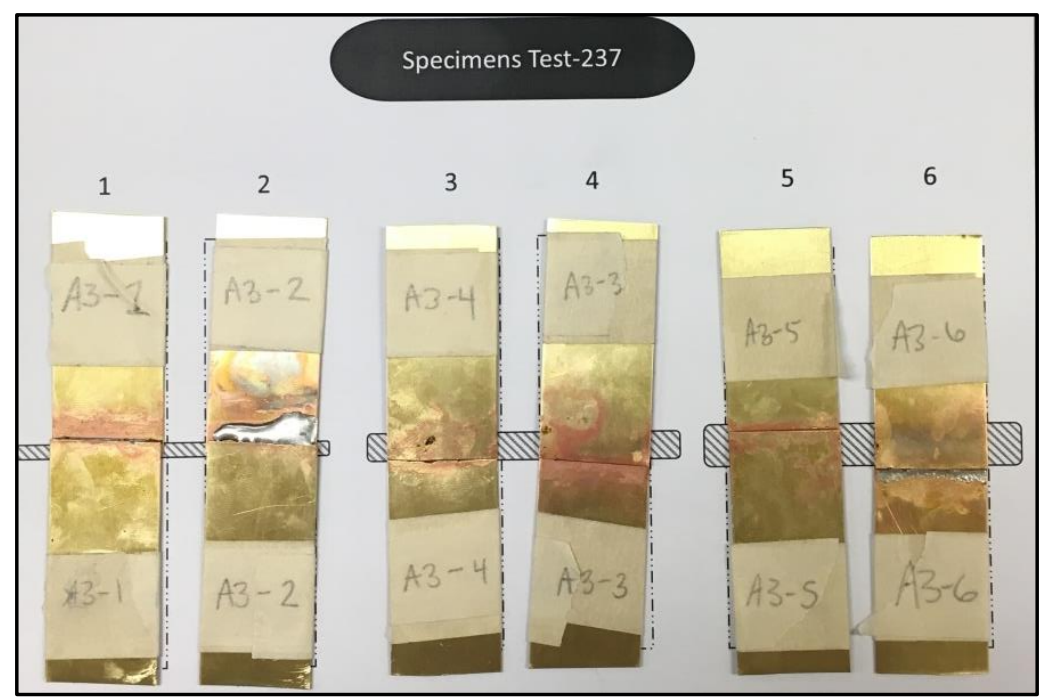

Figure 5: Student-made Lap Joint specimens before tensile/shear test. Multiple overlap lengths are produced to add variety to data collected.

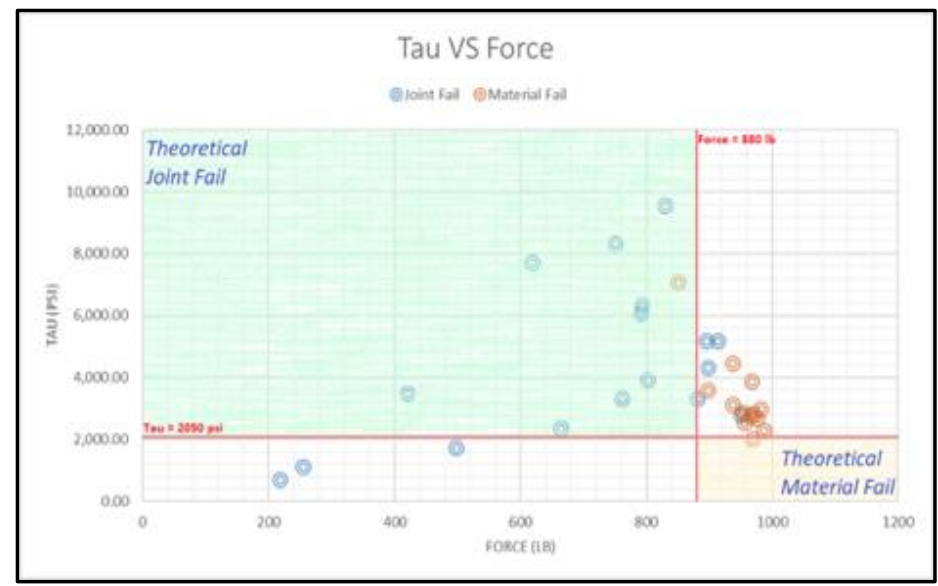

Figure 6: Example of student submission of Graph to Observed Failures modes. Creative and unique, self-driven, approaches to categorize and analyze data.

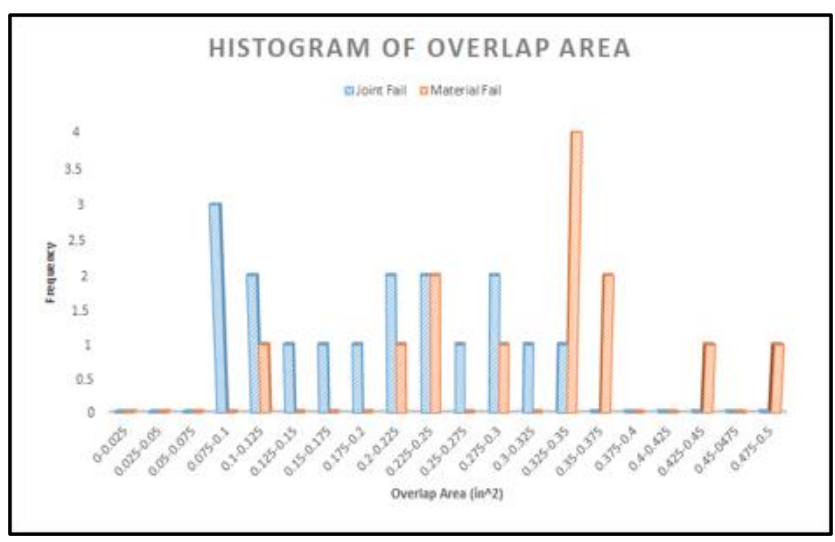

Figure 7: Student submitted histogram of Joint Overlap Area separating Joint and Material Failures. Statistical tool used to aid in data-driven design choices. 


\section{Activity 5 - Truss Design, Build, and Destructive Testing}

The final project of the course gathers all of the learnings and acquired data from previous activities to design a distance-spanning planar-truss. Students begin by developing truss design using a finite element program, and determining the first failing member and the applied failure load of the truss, keeping within the specified design requirements and limitations. Once a suitable design is selected the truss is measured, cut, and constructed using square brass tubing as truss members, flat brass sheets as gusset plates, and lead-free solder and hand torched for the soldering process (Fig. 8). Upon construction, the trusses are loaded into a compressive test until failure. A post-destructive analysis is performed to determine the cause of failure (joint or member failure), a comparison of actual and predicted loads, and if the predicted failing member(s) was the first to fail.

The primary requirements for the truss design was to span 14 inches, with 0.5 inches of support at each end, support a theoretical minimum load of 325 lbs., and use no more than 84 linear inches of brass. The metrics of performance are: The predicted max load was compared to actual testing max load, to depict the discrepancy between theory and practiced based on factors such as craftsmanship, joint methods, etc.; the overall actual weight of the fabricated truss, compared to a theoretical material usage, used to measure the amount of solder used at gusset joints and in turn reflecting the quality of build and added weight; and the truss weight again, with the actual test load to calculate the effective strength to weight ratio.

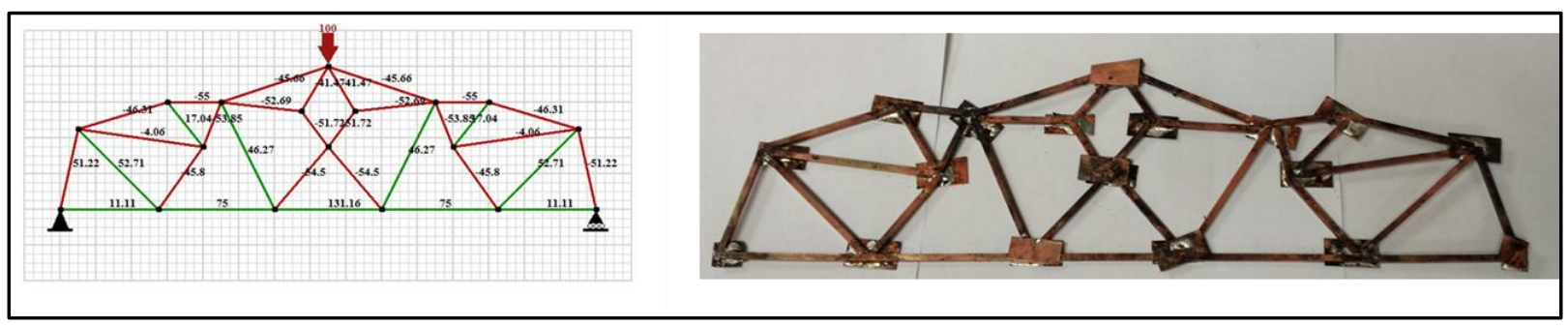

Figure 8: Side by side comparison displaying the design and construction phase of the project. (Left) FEM analysis of planar truss design. (Right) Realized planar-truss constructed and ready for testing.

\section{Design Vectors}

One-Dimensional: The nominal stress from an axial load is $\sigma=\frac{P}{A}$, where $\mathrm{P}$ is the axial load, and A is the cross-sectional area [11]. Assuming the load is given in a particular application, we can see that the cross-sectional area is variable and is not affected by the cross-sections shape. Thus, if we assume a set cross-sectional area of the component is in tension, the nominal stress calculated will dictate our material selection along with other properties that can be observed in an engineering stress vs. strain diagram. A material with a yield-strength greater than the nominal stress must be selected in order to not fail under the anticipated load. The Modulus of 
Elasticity will also dictate the elongation that the component will experience which needs to be considered if the change in length is critical. Conversely, if the material selection is restricted based on the application, it is apparent that the design vector relies on the one-dimensional unit of area as the design criterion.

Two-Dimensional: When observing the failure mode of slender columns, Euler Buckling, Euler's Critical Buckling Load equation is used: $P_{r c}=\left(\pi^{2} E I\right) /\left(k_{t} L^{2}\right)$ [11]. In a scenario where the length of a column and the way it is supported is dictated by the application, the variables remaining are the material selection, based on the Modulus of Elasticity, and the geometry of the column, based on the Moment of Inertia. This activity explores the theoretical failure loads of multiple columns with varying cross-sectional areas and geometries. The importance of the columns geometry is emphasized by demonstrating that a large cross-sectional area is not as important as where that area (mass) is relative to the central axis of the column. The overall strength of the column is then driven by a two-dimensional design vector composed of material selection and of column geometry.

Three-Dimensional: Although the average direct shear stress experienced in a single lap joint is $\tau_{\text {avg }}=V / A$, it is through the lab activity that this design vector is not like a component in tension, with a seemingly-similar equation [11]. The pull-test failure results of the lap joints are categorized in either a material (yield) failure in tension, or at a failure at the lap joint due to shear forces. In this example, the material selection affects the failure of the material in tension, the geometry of the samples - both in cross-sectional area of the material and in the overlap area - directly affect the predicted failure load respectively. The third dimension, the process selection, in this case for the joint fabrication, is showcased in the wide variation and the inconsistent results with the anticipated failure load at the joints. In contrast, the data collected shows a smaller variation of values when the failure occurs in the material rather than the joint. In addition to emphasizing the importance of process selection for joints, an emphasis is placed on process control by encouraging feedback in process control and corrections.

\section{Assessment}

Based on a review of the coursework submissions and the end of semester student survey, we are able to evaluate the quality of work and quality of learning by the students and their feelings toward to the course material, frame work, and learning outcomes. The implementation of these assessments provides a good platform for continual course improvement, and coincides with the fulfillment of ABET criteria [12]. The learning outcomes, listed above in Table 1, were presented at the beginning of the course, and included in the assessment survey. The format of the survey includes sections that focus of instructor evaluation, and learning outcome evaluations. The survey individually lists each Learning Outcome (L1-6) and provides a Ranking 
metric and room for comments. The survey results below include a total of 249 respondents out of a total number of 407 students (Table 2).

Table 2 - Learning Outcome Survey Results

\begin{tabular}{|l|c|c|l|l|l|l|l|l|}
\hline $\begin{array}{l}\text { Learning } \\
\text { Outcome }\end{array}$ & Mean & Median & SD & $\begin{array}{l}\text { No New } \\
\text { Learnin } \\
\mathrm{g}\end{array}$ & $\begin{array}{l}\text { Little New } \\
\text { Learning }\end{array}$ & $\begin{array}{l}\text { Some New } \\
\text { Learning }\end{array}$ & $\begin{array}{l}\text { Great New } \\
\text { Learning }\end{array}$ & $\begin{array}{l}\text { Significant New } \\
\text { Learning }\end{array}$ \\
\hline L1 & 3.3 & 4 & 0.91 & $0.8 \%$ & $3.6 \%$ & $14.9 \%$ & $26.1 \%$ & $54.6 \%$ \\
\hline L2 & 3.29 & 4 & 0.83 & $0.4 \%$ & $1.2 \%$ & $18.1 \%$ & $50.2 \%$ & $30.1 \%$ \\
\hline L3 & 3.23 & 3 & 0.89 & $0.4 \%$ & $2.8 \%$ & $19.7 \%$ & $49.8 \%$ & $27.3 \%$ \\
\hline L4 & 3.3 & 4 & 0.91 & $1.2 \%$ & $3.2 \%$ & $13.7 \%$ & $28.1 \%$ & $53.8 \%$ \\
\hline L5 & 3.36 & 4 & 0.91 & $1.6 \%$ & $2.8 \%$ & $11.6 \%$ & $57.8 \%$ & $26.1 \%$ \\
\hline L6(a) & 3.28 & 4 & 0.97 & $2.0 \%$ & $3.6 \%$ & $14.5 \%$ & $55.8 \%$ & $24.1 \%$ \\
\hline L6(b) & 3.29 & 4 & 0.96 & $1.6 \%$ & $4.4 \%$ & $12.9 \%$ & $55.0 \%$ & $26.1 \%$ \\
\hline
\end{tabular}

Table 2: Classroom assessment results showing high percentage of positive responses of Great or Significant New Learning for course Learning Outcomes.

Similar end-of-semester assessment surveys are used throughout the university, including all of the engineering design spine courses. This surveying method has a long history of effectiveness in other courses for gathering a sense of the students' learning and overall experience. The survey results are reviewed by instructors, course coordinators, and the curriculum development team to continuously improve issues or lapses in the educational objectives.

Lab Evaluation Comment \#5: "This laboratory was a good learning experience for me. I felt this class reinforced the stress, strain, and other principles I learned in Mechanics of Solids ... it's easier to understand the basic concepts of the course, which then allowed me to gain a deeper understanding of the material through the experiments and activities. I know that certain elements of this course were recently changed, and I feel that those changes were beneficial, such as creating the model in Excel, because I have not yet had that experience in another course and I think that having that skill will help me in industry."

Lab Evaluation Comment \#8: "Very interesting lab where the students made their own measurements of material properties and then used them to create a truss from those material properties. I learned a lot about Excel and how to use it to create dynamic results..."

Lab Evaluation Comment \#177: “... I gained the most knowledge in using EXCEL, which was extremely beneficial. I also gained adequate skill in soldering."

A randomly selected section, of 22 students, was evaluated to show the average activity grades and final class grade are below in Table 3. Course sections prior to the new implementations are compared based on Activity 5, a project that had been traditional given, as well as the overall final grade Table 4. 
Table 3 - New Course Curriculum Activity Grades

\begin{tabular}{|c|c|c|c|c|c|}
\hline Activity 1 & Activity 2 & Activity 3 & Activity 4 & Activity 5 & Final Grade \\
\hline $88.23 \%$ & $87.09 \%$ & $92.36 \%$ & $89.09 \%$ & $93.19 \%$ & $95.57 \%$ \\
\hline
\end{tabular}

Table 3: Randomly selected course section, with newly implemented changes, showing grade average per activity and final overall class grade.

Table 4 - Prior Grades of Similar Activities and Final Grade

\begin{tabular}{|c|c|c|c|c|c|}
\hline \multicolumn{2}{|c|}{ 3 Semesters Prior (27) } & \multicolumn{2}{c|}{ 2 Semesters Prior (52) } & \multicolumn{2}{c|}{ 1 Semester Prior (5) } \\
\hline Activity 5 & Final Grade & Activity 5 & Final Grade & Activity 5 & Final Grade \\
\hline $88.37 \%$ & $91.72 \%$ & $88.37 \%$ & $92.96 \%$ & $91.8 \%$ & $95.85 \%$ \\
\hline
\end{tabular}

Table 4: Randomly selected course sections, prior to new changes, showing grade average for activity 5 and final overall class grade.

Concluding Remarks

Given the survey results, we are able to assess that the overall outcomes are being met and are above average across the board. There are specific examples of student feedback which explicitly express the benefit of the laboratory learning environment to aid in further understanding the principles taught in a traditional lecture based classroom environment. The use and application of graphical and computation programs such as EXCEL has also been noted as improving based on comments and the evaluation result with $53.8 \%$ reporting significant learning experience, and $28.1 \%$ reporting a great learning experience.

When comparing to semesters prior, Activity 5, the planar-truss project, has shown an improvement in the recent deployment of this new structured course. From as far back as 3 semesters the improvements in grades are, oldest to newest, $5.17 \%, 5.17 \%$, and $1.49 \%$ respectively. This supports the idea that students are able to relate and apply more of their skillset to a project-based activity when prior engagements have prepared them to develop skills and emphasize the relevance of that knowledge towards a group goal. The overall classes averages form the prior sampled, oldest to newest, sections show a change of $4.03 \%, 2.73 \%$, and $-0.29 \%$ respectively. The overall class grades have also shown improvement with the exception of the most recent semester prior to the implementation; this may be attributed to the small number of 5 students enrolled during that semester.

\section{References Cited}

[1] R. Jain, K. Sheppard, E. McGrath, and B. Gallois, "Promoting Systems Thinking in Engineering and Pre-Engineering Students," in American Society for Engineering Education Spring 2008 Mid-Atlantic Section Proceeding. 2008. 
[2] J.E. Mills, and D.F. Treagust, "Engineering Education-Is Problem-Based or Project-Based Learning the Answer," Australasian Journal of Engineering Education, vol. 3, pp. 2-16 2003.

[3] D. J. Cappelleri and N. Vitoroulis, "The Robotic Decathlon: Project-Based Learning Labs and Curriculum Design for an Introductory Robotics Course," IEEE Transactions on Education, vol. 56, no. 1, pp. 73-81, Feb. 2013.

[4] M. Yim, et al. "AC 2008-2230: A Practice-Integrated Undergraduate Curriculum in Mechanical Engineering," ASEE PEER, pp. 13.81.1 - 13.81.15 Jun. 2008.

[5] P. Fiorini and D. Kragic, "Education by competition," IEEE Robotics \& Automation Magazine, vol. 13, no. 3, pp. 6, Sept. 2006.

[6] S. Lightner, et al. "Team-Based Activities to Promote Engaged Learning." College Teaching, vol. 55, no. 1, pp. 5-18, 2007.

[7] A. Rassuli, and Manzer, P., “'Teach Us to Learn': Multivariate Analysis of Perception of Success in Team Learning," Journal of Education for Business, vol. 80, no. 1, pp. 21-27, 2005

[8] S. A. Hernadez, "Team Learning in a Marketing Principles Course: Cooperative Structures That Facilitate Active Learning and Higher Level Thinking," Journal of Marketing Education, vol. 24, no. 1, pp. 73-85, 2002.

[9] B. S. Bloom, and D. R. Krathwohl. Taxonomy of educational objectives: The classification of educational goals, by a committee of college and university examiners, Handbook 1: Cognitive domain. New York, NY: Longmans, 1956.

[10] R. V. Schaaf, and J. Klosky, "Classroom Demonstrations in Introductory Mechanics," Journal of Professional Issues in Engineering Education and Practice, vol. 131, pp. 83-89, 2005.

[11] R. C. Hibbeler, Statics and Mechanics of Materials. Pearson, 2014.

[12] K. Sheppard, and B. Gallois, "The Design Spine: Revision of the Engineering Curriculum to Include a Design Experience each Semester," in American Society for Engineering Education Annual Conference Proceedings, Charlotte, North Carolina, June 1999, Session 3225. pp. 4.513.1-4.513.7. 